\title{
Application of Taguchi's experimental design method for optimization of Acid Red 18 removal by electrochemical oxidation process
}

\author{
Zabihollah Yousefi $^{(\mathbb{1}}$, Ali Zafarzadeh ${ }^{2}$, Abdolaziz Ghezel $^{3^{*}(\mathbb{D}}$ \\ ${ }^{1}$ Department of Environmental Health Engineering, School of Public Health, Mazandaran University of Medical Sciences, Sari, Iran \\ ${ }^{2}$ Environmental Health Research Center, School of Health, Golestan University of Medical Sciences, Gorgan, Iran \\ ${ }^{3}$ School of Health and Health Sciences Research Center, Mazandaran University of Medical Sciences, Sari, Iran
}

\begin{abstract}
Background: Electro-oxidation is developed as an electrochemical method to overcome the problems of the conventional decolorization technologies and is an appropriate alternative for the treatment of colored wastewater from various industries. The purpose of this study was to evaluate the efficiency of the electrochemical oxidation process in removal of chemical oxygen demand (COD) and Acid Red 18 (AR18) dye from aqueous solutions.

Methods: In this research, a laboratory scale of electro-coagulation reactor for the treatment of synthetic wastewater was made and studied. The effects of different variables including $\mathrm{pH}$, current density, dye concentration, and electrolysis time were investigated. The experiment steps were designed by DesignExpert 10 software using the selected variables. Finally, the dye and COD analysis was performed by spectrophotometer. The optimization was performed using Taguchi fractional factorial design during the removal of dye and COD.

Results: Maximum removal of dye ( $89 \%)$ and $\operatorname{COD}(72.2 \%)$ were obtained at $\mathrm{pH}=3$, current density $=20$ $\mathrm{mA} / \mathrm{cm}^{2}$, initial dye concentration $=100 \mathrm{mg} / \mathrm{L}$, and reaction time $=45 \mathrm{~min}$. ANOVA test showed a significant relationship between statistical model and test data. Also, the results indicate that the distribution of the residues of the model was normal.

Conclusion: By designing experiments through Taguchi method, the removal process will be optimized and by decreasing the number of experiments, the optimal conditions for pollutant removal will be prepared. The results suggest that the Electro-oxidation system is a very suitable technique for the enhancement of wastewater treatment.

Keywords: Electrolysis, Wastewater, Azo compounds, Models, Statistical, Analysis of variance

Citation: Yousefi Z, Zafarzadeh A, Abdolaziz Ghezel A. Application of Taguchi's experimental design method for optimization of Acid Red 18 removal by electrochemical oxidation process. Environmental Health Engineering and Management Journal 2018; 5(4): 241-248. doi: 10.15171/EHEM.2018.32.
\end{abstract}

\section{Article History:}

Received: 10 September 2018

Accepted: 3 November 2018

ePublished: 2 December 2018

\section{Introduction}

Synthetic dyes are extensively used in several industries such as textile, leather tanning, food, cosmetics etc (1). Dyes with $N=N$ bonds and sulfonic groups in their structures are considered as acid and belong to the azo-dye class (2). Among all kinds of coloring materials, Azo dyes, such as Acid Red 18 (AR18), have the widest application due to the variety in the chemical structure and easy production (3). These dyes usually include one or more functional groups and complex aromatic structures, which make them very resistant to biodegradation. Therefore, when improperly discharged, they can stay in the environment for long periods of times, which can be a serious threat for health and interfere vital biological procedures (1).
Since, unsanitary disposal of wastewater can cause major environmental problems and health issues, therefore, there is an immediate need for methods which can effectively treat industrial wastewater (4). So far, various physiochemical methods such as ultra-filtration, reverse osmosis, coagulation and flocculation, ion exchange, biological methods, adsorption and membrane processes, advanced oxidation processes (AOPs), and other methods have been utilized for treating the colored wastewaters (5). The most commonly used physiochemical methods for dye removal are often non-degrading, ineffective, and expensive, and result in the production of a large volume of sludge, which has the problem of treatment and disposal (6). In recent decades, the $\mathrm{AOP}_{S}$ have been 
significantly developed and are of great importance in the treatment of industrial wastewater, in particular, the wastewaters containing the refractory organic residues that the conventional treatment methods are not able to treat them (7). The electrochemical technique is an important process for separating and controlling various types of pollutants. The main advantages of this method are: safety, simplicity, high speed, short retention time to remove the contaminants, easy operation, low chemicals consumption, relative energy efficiency and costs (8). The mechanism for pollutants removal in the electrochemical process is complex, in which depending on different wastewater contaminants, electrode materials are used (9). Electrochemical treatment of wastewaters containing organic compounds, is classified into two categories: indirect oxidation using an electro-generated oxidation agent such as hypochlorite or hydrogen peroxide and direct oxidation (on the anode). Hydrogen peroxide is produced through electrochemical reduction of oxygen on carbon cathode (10). In indirect oxidation, adsorbed hydroxyl radicals are supposed to be generated from water electrolysis (equation 1), and in some cases, they may interact with active anode to form higher metal oxide (MO) (equation 2). Thus, organic pollutants will be oxidized in three different ways by adsorbed hydroxyl radicals, higher MO oxide (equation 3) or free hydroxyl radicals (9).

$\mathrm{M}+\mathrm{H}_{2} \mathrm{O} \rightarrow \mathrm{M}(\mathrm{OH})+\mathrm{H}^{+}+\mathrm{e}^{-}$

$\mathrm{M}(\mathrm{OH}) \rightarrow \mathrm{MO}+\mathrm{H}^{+}+\mathrm{e}^{-}$

$\mathrm{MO}+\mathrm{R} \rightarrow \mathrm{M}+\mathrm{RO}$

The electrochemical method has been successfully tested in various industrial wastewater treatment plants (11). So far, a large number of research has been conducted on the electrochemical processes. Mozia et al, in a study investigated photo catalytic degradation of AR18, and concluded that photo catalytic process can be an effective method for degradation of Azo dyes (5). In another study, Guivarch et al investigated the degradation of azo dyes in water by electro-Fenton process. In this study, platinum and carbon were used as anode and cathode, respectively. The results of this study showed that degradation kinetics of Azo dye followed the first-order reaction and, eventually, this dye was mineralized into $\mathrm{CO}_{2}$ and $\mathrm{H}_{2} \mathrm{O}$ by the electroFenton process (12). In a study conducted by Dalvand et al, the efficacy of electrochemical process for dye treatment was evaluated, and it was revealed that the electrochemical process is an effective method for removing the dye, and in the optimal operational conditions, the removal of dye and chemical oxygen demand (COD) was $99 \%$ and $66.6 \%$, respectively (13). Furthermore, in a study conducted by Mehralipour et al, the electrochemical process was used to remove the dye, and it was concluded that this process has a high ability to remove the dye (14). Therefore, the aim of this study was to investigate the efficiency of electrochemical process using titanium anode electrode and graphite felt cathode in removing the AR18 dye and
COD from aqueous solutions by taking into account the effects of various factors.

\section{Materials and Methods}

Experimental setup and procedure

In this study, the AR18 dye, with characteristics listed in Table 1, produced by Sigma Aldrich Company, was used. Hydrochloric acid, sodium hydroxide, sodium chloride and other chemicals used in the experiments, were of analytical grade and obtained from the Merck Co., Germany. The wastewater used in this study was prepared at a concentration of $1000 \mathrm{mg} / \mathrm{L}$ as the stock solution, and the samples containing required concentration (25-150 $\mathrm{mg} / \mathrm{L}$ ) were prepared using stock solution and used. To determine the maximum absorbance wavelength of AR18 dye, DR-6000 spectrophotometer apparatus ( $\mathrm{HACH}$, Germany) was used. The best wavelength in terms of maximum absorbance was selected for AR18 dye. As shown in Figure 1, the wavelength of $507 \mathrm{~nm}$ was selected as the maximum absorbance wavelength of AR18 dye for this study. Different concentrations of dye solution were prepared to draw a standard curve diagram and their absorbance was measured using a spectrophotometer at $507 \mathrm{~nm}$, then, a standard curve was drawn. The batch flow reactor consisted of an electrochemical cell and is made of Plexiglas with useful volume of $500 \mathrm{~mL}$ and was shown in Figure 2. Titanium and graphite felt electrodes with dimensions of $5 \times 2 \times 5 \mathrm{~cm}$ were used as anode and cathode,

Table 1. Chemical properties of AR18 dye

\begin{tabular}{ll}
\hline Parameters & Value \\
\hline Molecular formula & $\mathrm{C}_{20} \mathrm{H}_{11} \mathrm{~N}_{2} \mathrm{Na}_{3} \mathrm{O}_{10} \mathrm{~S}_{1}$ \\
Molecular weight & 604.5 \\
COD of 1g-AR18/L & $597 \pm 17$ \\
$\lambda_{\max }$ & 507 \\
Chemical structure & \\
CAS - NO. & $2611-82-7$ \\
\hline
\end{tabular}

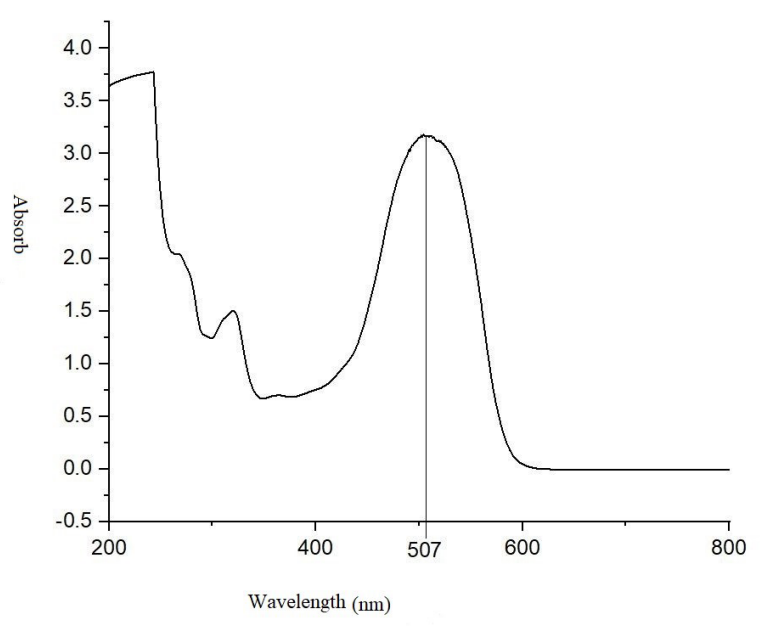

Figure 1. Maximum Absorbance Wavelength of Acid Dye 18. 


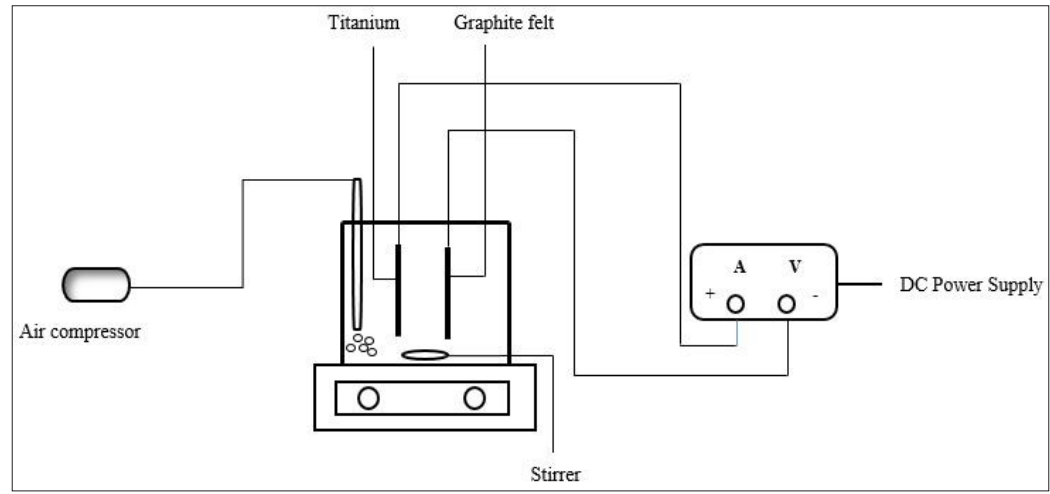

Figure 2. Schematic diagram of experimental setup.

respectively, and they were placed vertically inside the reactor and the distance between the electrodes was kept at $2 \mathrm{~cm}$. The total effective surface of the electrodes was $50 \mathrm{~cm}^{2}$. Both electrodes were connected to direct current (DC) power by the extension cord. To improve ionic strength and to increase the electrical conductivity of the solution, the $\mathrm{NaCl}$ electrolyte was added to the solution at a constant concentration of $0.1 \mathrm{M}$ in all experiments. To obtain the desired value of $\mathrm{pH}$, the initial $\mathrm{pH}$ of the solution was adjusted using $0.01 \mathrm{~N}$ sodium hydroxide and chloride acid. Moreover, a magnetic stirrer was used to make a uniform mixing in the reactor and its content was stirred at a constant speed of $300 \mathrm{rpm}$ in all experiments. The electrolysis of the solution was initiated by setting an electric current through applying the determined current density, while the solution was aerating at a constant flow rate of $1 \mathrm{~L} / \mathrm{min}$ using an aeration system (HAILEA air compressor, ACO-5505, China) with a fine bubble diffuser. At the end of the experiments, the suspension was filtered, and then, the outlet concentration was measured by $\mathrm{UV} / \mathrm{V}$ is spectrophotometer at $507 \mathrm{~nm}$. At each step of the experiments, the reactor was filled with $500 \mathrm{~mL}$ of dye solution and the effect of parameters including $\mathrm{pH}$, initial concentration of dye, current density, and contact time were investigated. Each experiment was repeated three times, and the effect of variables on the optimization of decolorization and removal of COD from synthetic sewage was determined using Design-Expert 10 software with Taguchi design method and the related graphs were plotted using Excel 2016 software.

\section{Analytical method}

To evaluate the individual effect of $\mathrm{pH}$, initial dye concentration, current density, and reaction time on the removal of AR18 dye and COD, data were analyzed using Design-Expert software (Design-Expert 10 StatEase, Inc., USA). Taguchi orthogonal design model with 4 factors at 4 levels (Table 2) was used to optimize the electro-oxidation degradation process. The COD was determined by the standard method (5220D). The initial and final concentrations of AR18 dye were measured by
UV-Vis spectrophotometer at the wavelength of $507 \mathrm{~nm}$. The removal efficiency of dye and COD were calculated using the following equation:

$A R 18$ or COD removal $(\%)=\frac{\left.C_{0}-C_{t}\right)}{C_{0}} \times R 18$

Where $\mathrm{C}_{0}$ is the initial concentration of dye and COD, and $\mathrm{C}_{\mathrm{t}}$ is the concentration at time $(t)$ of the variables.

\section{Results}

The effect of the factors studied on the removal of dye and COD

The results of evaluation of the effects of different parameters such as initial $\mathrm{pH}$, flow density, initial concentration of dye, and reaction time on removal of dye and COD are shown in Figure 3 at the average level of each factor. As shown in Figure 3A, with an increase in $\mathrm{pH}$ value from 3 to 9 , the removal efficiency of dye and COD was reduced from $59.93 \%$ and $49.34 \%$ to $47.37 \%$ and $37.39 \%$, respectively. The results of evaluation of the effect of the current density on the dye and COD removal efficiency using the electrochemical process are shown in Figure 3B. As shown in this figure, the removal efficiency of dye and COD increased by increasing the current density. In other words, by increasing the current density from 10 to $25 \mathrm{~mA} / \mathrm{cm}^{2}$, the COD removal efficiency was increased from $32.71 \%$ to $47.79 \%$. The results of Figure $3 \mathrm{C}$ show that by increasing the initial concentration of dye, the removal efficiency of dye and COD significantly decreased from $63.33 \%$ to $42.44 \%$ and from $48.82 \%$ to $33.98 \%$, respectively. In addition, the results of Figure 3D show that by increasing the reaction time, the removal efficiency initially increased, and then, decreased. For

Table 2. Experimental design parameters

\begin{tabular}{lcccc}
\hline Factors & Level 1 & Level 2 & Level 3 & Level 4 \\
\hline A:pH & 3 & 5 & 7 & 9 \\
B:current density $\left(\mathrm{mA} / \mathrm{cm}^{2}\right)$ & 10 & 15 & 20 & 25 \\
C:AR18 concentration (mg/L) & 25 & 50 & 100 & 150 \\
D:electrolysis time (min) & 15 & 30 & 45 & 60 \\
\hline
\end{tabular}



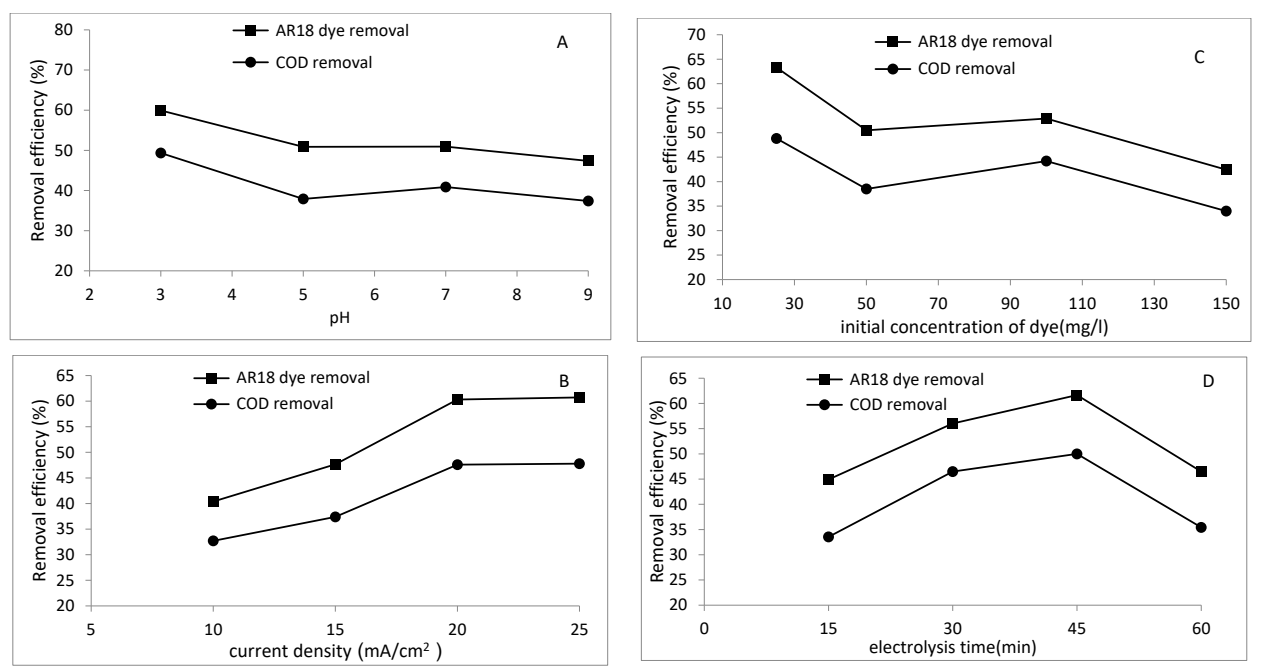

Figure 3. The effect of the parameters on the removal efficiency of AR18 and COD using an electrochemical system at the average level of each factor (A: effect of initial $\mathrm{pH}, \mathrm{B}$ : effect of current density, C: effect of initial concentration of dye, and D: effect of electrolysis time).

example, with an increase in the reaction time from 15 to 45 minutes, the dye removal efficiency increased from $44.92 \%$ to $61.66 \%$, then, by further increase in the reaction time to 60 minutes, the removal efficiency reduced to $49.46 \%$.

Optimization of operational parameters

For maximizing removal efficiency of dye and COD, a numerical optimization was chosen. The favorite level for dye and COD removal efficiencies were defined as "maximize", while level for each independent variable were chosen as "in the range".

The desirability ramp for the numerical optimization diagram is presented in Figure 4. As shown in this figure, maximum removal efficiency of $88.39 \%$ for the dye and $71.65 \%$ for COD can be predicted with a desirability of 1.0 at optimum conditions: initial $\mathrm{pH}$ of 3 , applied current density of $20 \mathrm{~mA} / \mathrm{cm}^{2}$, initial dye concentration of 25 $\mathrm{mg} / \mathrm{L}$, and reaction time of 45 minutes.

For confirming the adequacy and reproducibility of the statistically optimized conditions and removal of the dye and COD from synthetic wastewater, a verification test under the above-mentioned conditions was carried out. As a result, the highly acceptable removal efficiency of the dye and COD was $89 \%$ and $72.2 \%$, respectively. The removal efficiencies were found to be in agreement with those predicted in the study, which implies a good prediction of the model. Furthermore, several proposed ramps that predict the highest removal efficiency, were used to evaluate the final removal efficiency for dye and COD, which was in agreement with the predicted optimum conditions. The finding suggest that the developed system is an appealing and strong solution for the improvement of synthetic wastewater electrochemical treatment.

Analysis of variance and the suitability of the model In Tables 3 and 4 , various statistical data (sum of squares, degrees of freedom, mean square, $P$ value, and $F$ value, etc), which were calculated by the Design Expert software, are presented. The $F$ value of the model for removal of the dye and COD was 561.79 and 64.23, respectively, and the probability of presence of error for $F$ value was only $0.01 \%$.

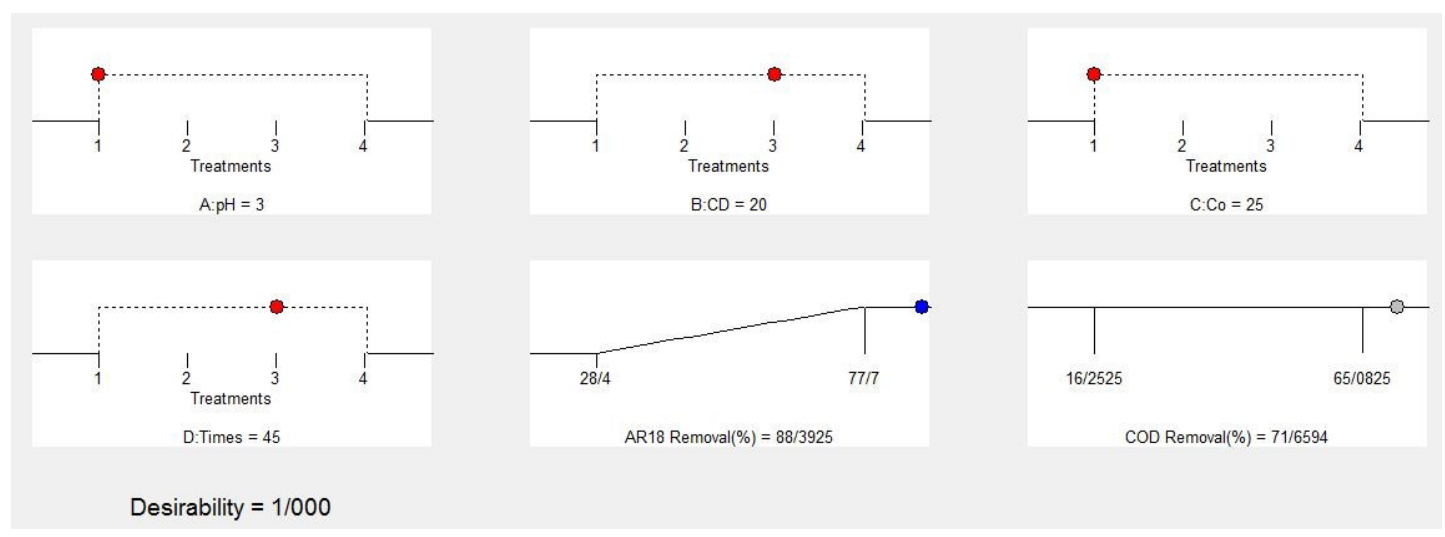

Figure 4. Desirability ramp for numerical optimization of dye and COD removal efficiencies 
Table 3. ANOVA for the decolorization using electrochemical process

\begin{tabular}{|c|c|c|c|c|c|}
\hline Source & Sum of Square & $d f$ & Mean Square & $F$ value & $P$ value, Prob $>F$ \\
\hline Model & 9562.01 & 12 & 796.83 & 561.79 & $<0.0001$ \\
\hline A-pH & 1036.15 & 3 & 345.38 & 243.50 & $<0.0001$ \\
\hline$B-C D$ & 3582.51 & 3 & 1194.17 & 841.92 & $<0.0001$ \\
\hline C-Co & 2665.96 & 3 & 888.65 & 626.52 & $<0.0001$ \\
\hline D-Times & 2277.39 & 3 & 759.13 & 535.21 & $<0.0001$ \\
\hline Residual & 49.64 & 35 & 1.42 & - & - \\
\hline Pure Error & 29.80 & 32 & 0.93 & - & - \\
\hline Cor Total & 9611.65 & 47 & - & - & - \\
\hline
\end{tabular}

Table 4. ANOVA for the COD removal efficiency using electrochemical process

\begin{tabular}{|c|c|c|c|c|c|}
\hline Source & Sum of Square & $d f$ & Mean Square & $F$ value & $P$ value, Prob $>F$ \\
\hline Model & 7038.60 & 12 & 586.55 & 64.23 & $<0.0001$ \\
\hline A-pH & 1100.95 & 3 & 366.98 & 40.19 & $<0.0001$ \\
\hline B-CD & 2049.41 & 3 & 683.14 & 74.81 & $<0.0001$ \\
\hline $\mathrm{C}-\mathrm{Co}$ & 1517.00 & 3 & 505.67 & 55.38 & $<0.0001$ \\
\hline D-Times & 2371.24 & 3 & 790.41 & 86.56 & $<0.0001$ \\
\hline Residual & 319.60 & 35 & 9.13 & - & - \\
\hline Pure Error & 26.12 & 32 & 0.82 & - & - \\
\hline Cor Total & & 47 & & - & - \\
\hline
\end{tabular}

In addition, the $P$ value of the model for removal of the dye and COD was smaller than 0.0001, which indicates that the model is meaningful and can be used to predict the desired goals. The results of model summary statistics are listed in Table 5. As shown in this table, the obtained coefficient of variation values for AR18 dye and COD removal efficiency were relatively low, equal to $2.28 \%$ and $7.30 \%$, respectively. Furthermore, the "Predicted- $\mathrm{R}^{2}$ " for dye and COD removal efficiency was 0.99 and 0.91 , so that it was in reasonable agreement with the "Adjusted- $\mathrm{R}^{2}$ " of 0.99 and 0.94 , respectively, which indicates that the proposed equation ensures an appropriate approximation for the relationship between the independent variables and the response variable.

Figure 5 ( $\mathrm{A}$ and $\mathrm{B}$ ) shows the comparison between the actual values and predicted values for decolorization and COD removal efficiency, respectively. Comparison of the actual and predicted data of the removal efficiency showed that the predicted data were in good agreement with the actual data. Figure 6 also shows the normal probability of residuals distribution for removal of dye and COD. The results represented normal distribution of the residuals of the model, which indicates the high efficiency of the selected model for describing and predicting the removal of dye and COD by electrochemical processes.

\section{Discussion \\ Effect of $\mathrm{pH}$}

The results of Figure 3A show that the removal of AR18 dye and COD in the acidic environment was better. To describe the reason for this event, it can be stated that the capability of hydroxyl radicals in acidic conditions is more potentially high, thus, in acidic solutions, free radicals can be produced and organic materials can be easily oxidized (8). In addition, increase in the $\mathrm{pH}$ value leads to the production of a large amount of hydroxyl radical scavengers (such as carbonates and bicarbonates) that arise due to the mineralization of organic matter and, as a result, reduces the degradability (15). Eslami et al investigated the dye removal efficiency in aqueous solutions using the electrochemical process and declared the acidic $\mathrm{pH}$ values as the optimum condition to remove the dye (16). Ganbari et al investigated the degradation of dye in aqueous solutions by electrolysis process to determine the effect of $\mathrm{pH}$ on dye removal (17). According to the results, the highest removal efficiency was reported

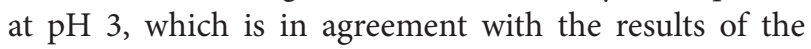
present study.

Effect of current density

In Figure $3 \mathrm{~B}$, the results of evaluation of the effect of the

Table 5. Model summary statistics tested for decolorization and COD removal efficiency

\begin{tabular}{lccccccc}
\hline Response & $\begin{array}{c}\text { Standard } \\
\text { deviation }\end{array}$ & R-squared & $\begin{array}{c}\text { Adjusted } \\
\text { R-squared }\end{array}$ & $\begin{array}{c}\text { Predicted } \\
\text { R-squared }\end{array}$ & $\begin{array}{c}\text { Coefficient of } \\
\text { variation (\%) }\end{array}$ & Adequate precision & Mean \\
\hline $\begin{array}{l}\text { AR18 dye removal } \\
\text { COD removal }\end{array}$ & 1.19 & 0.994 & 0.9931 & 0.9903 & 2.28 & 78.752 \\
& 3.02 & 0.9566 & 0.941 & 0.9183 & 7.30 & 29.665 \\
\hline
\end{tabular}



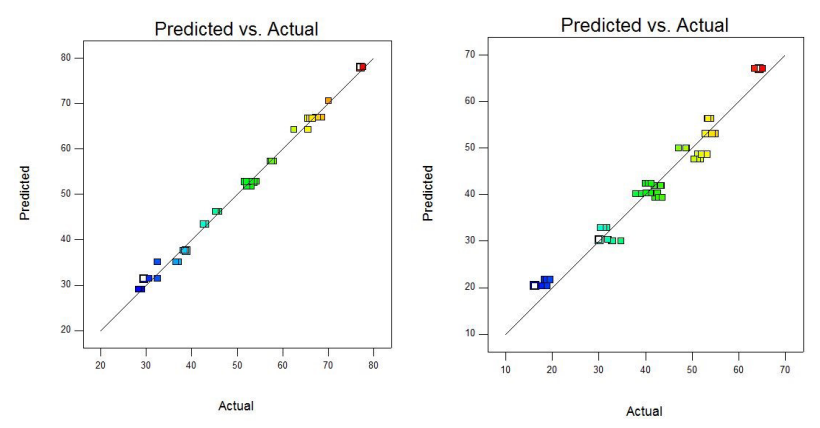

Figure 5. The experimental $(A)$ decolorization and $(B)$ COD removal efficiency plotted against the predicted values calculated from the Factorial model - Taguchi design.

current density are presented, and show that the removal efficiency of dye and COD was generally increased with an increase in the current density. Regarding to the performance of the current density, it can be concluded that by increasing the current density, which is also increased by the voltage applied by the device, more efficiency is obtained. In this experiment, the density of 20 $\mathrm{mA} / \mathrm{cm}^{2}$ was selected as the optimum value. This can be due to the production of hydroxyl radical, which increased the dye removal efficiency (18). It also increased the degradation efficiency with increase of the current density due to increasing the electrically production of hydrogen peroxide $\left(\mathrm{H}_{2} \mathrm{O}_{2}\right)$ followed by the production of hydroxyl radicals in the solution (19). In a study by Daneshvar et al on the decolorization of Acid Yellow 23 solutions using the electro-coagulation process, it was revealed that by increasing the current density, the removal efficiency of dye and COD also increased (20). Similar results were reported in the study of Massoudinejad et al, on the removal of the dye and COD by electro-coagulation; they also reported that with increase of the current density, the removal efficiency of dye and COD also increased (21).

Effect of initial dye concentration

As shown in Figure 3C, with an increase in the initial dye concentration from 25 to $150 \mathrm{mg} / \mathrm{L}$, the removal efficiency was reduced. This can be explained as follows: by increasing the dye concentration in the solution, the number of dye molecules also increased and, as a result, the consumption of hydroxyl radicals by the dye molecules was more than the production of the radicals. A decrease in the number of free radicals compared to that of dye molecules, reduces the performance of the system in degrading the dye (22). In a study conducted by Mehralipour et al on the removal of the dye using the electrochemical oxidation, it was revealed that the removal efficiency decreased with increase of the dye concentration (14). In another study by Rajkumar et al, the electrochemical degradation process was utilized to remove dye and it was reported that the removal efficiency decreased with increase of the dye concentration (23).

\section{Effect of reaction time}

Figure $3 \mathrm{D}$ shows that the removal efficiency of dye and COD increased by increasing electrolysis time. In this study, the removal efficiency was increased up to 45 minutes, and then, decreased. The reason for this event can be explained by the fact that by increasing the reaction time, the decomposition of hydrogen peroxide into hydroxyl radicals is increased and, as a result, the production of hydrogen radicals in the environment is enhanced, and subsequently, led to an increase in the
(A1)

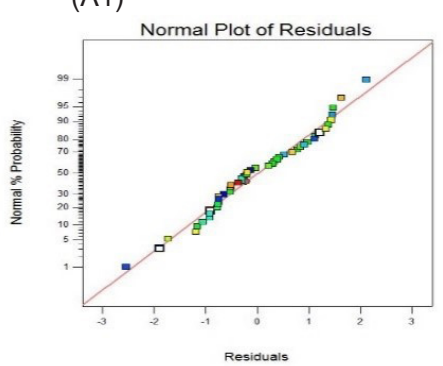

(B1)

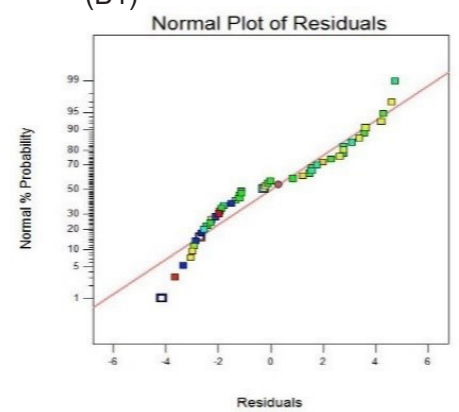

(A2)

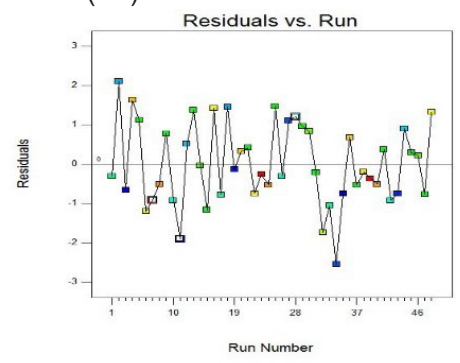

(B2)

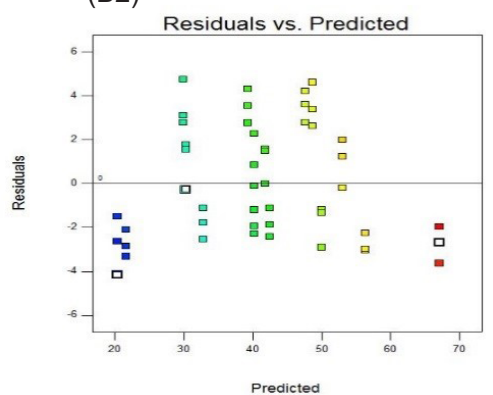

(A3)

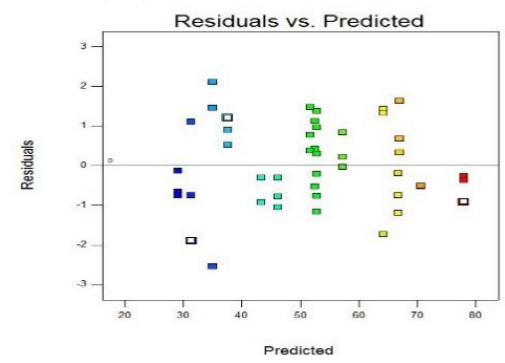

(B3)

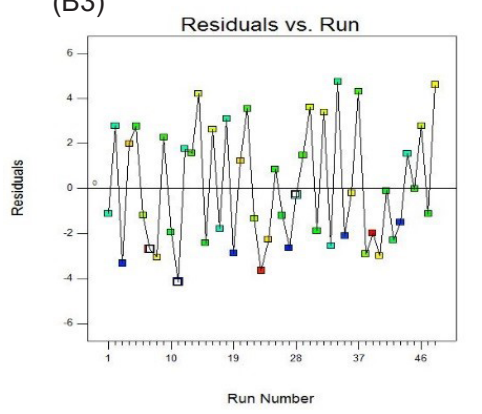

Figure 6. Diagnostics plots for (A) dye removal and (B) COD removal efficiency: (A1 and B1) Normal probability test: (A2 and B2) Residuals versus the predicted values, and (A3 and B3) Residuals versus Run number. 
removal of pollutants (24). In a study, Samarghandi et al, evaluated the electrochemical process in removing the dye from aqueous solutions and found out that by increasing the electrolysis time, the removal efficiency increased (25). Xiong et al in their study on the removal of dye and COD by electrochemical processes, concluded that by increasing the reaction time, the removal efficiency initially increased, and then, decreased due to parasitic and scavenging processes (26), which is consistent with the results of the present study.

Analysis of variance and the suitability of the model In Tables 3 and 4, the meaningful factors and their interaction on the response are presented. In this case, A, B, $\mathrm{C}, \mathrm{D}$, which are $\mathrm{pH}$, current density, initial concentration of dye, and reaction time, respectively, are meaningful terms of the model. The values of Prob $>F$ was less than 0.05 , which indicates that the model terms are meaningful. In addition, the results of analysis of variance showed that the regression model had a statistically significant relationship $(P<0.0001)$ and also a high coefficient of determination for the removal ef $\mathrm{ficiency}$ of dye $\left(\mathrm{R}^{2}=\right.$ $0.99)$ and $\operatorname{COD}\left(\mathrm{R}^{2}=0.95\right)$. Adequate precision (Adeq Precision) measures the signal-to-noise ratio $(\mathrm{S} / \mathrm{N})$, and in general, the ratio higher than 4 is desirable (20). The obtained ratio for removal of dye and COD was 78.75 and 29.66 , respectively, which indicates the suitability of the signal value (Table 5). This model can be used to navigate the design space.

\section{Validation of statistical model}

Figure 5 shows comparison of the actual values with predicted values for the removal efficiency of dye and COD. As shown in this figure, the predicted data were in good agreement with the laboratory data. To evaluate the adequacy of the model, the hypotheses of the mathematical model were examined using the diagnostic curve. In Figure6 (A1 and B1), the colored points are the residuals, and if the points be close to the line, they indicate the normality of the residuals. As shown in this figure, since the colored points are close to the bisector line, the normality of the residuals can be approved (27). In Figure 6 (A2-3 and B2-3), the residual plots of the two models are distributed randomly and without any particular process and pattern, and due to the absence of any trend, it can be confirmed that the second order models selected are suitable, and therefore, the assumption of the normality of residuals is acceptable and can be used to predict the responses of dye and COD removal efficiency (28).

\section{Conclusion}

In the present study, the treatment of the synthetic wastewater was evaluated using titanium and graphite felt electrodes in the electro-coagulation process in an electrochemical batch reactor.

Through a numerical optimization process, an applied current density of $20 \mathrm{~mA} / \mathrm{cm}^{2}$, initial $\mathrm{pH}$ of 3 , initial dye concentration of $25 \mathrm{mg} / \mathrm{L}$, and reaction time of 45 minutes were suggested as the optimal conditions. Under the optimal conditions, the highest removal of COD and dye was obtained to be $72.2 \%$ and $89 \%$, respectively. The results showed that current density and reaction time are the effective parameters that influence the dye and COD removal efficiency.

According to the results, the electrochemical reactor is considered as an effective alternative for the degradation of AR18 dye from aqueous solutions.

\section{Acknowledgments}

The authors appreciate the School of Health, Golestan University of Medical Sciences, Gorgan, for providing laboratory facilities.

\section{Ethical issues}

The authors hereby certify that all data collected during the study areas stated in this manuscript, and no data from the study has been or will be published elsewhere separately.

\section{Competing interests}

The authors declare that they have no conflict of interests.

\section{Authors' contribution}

All authors contributed in data collection, analysis, and interpretation. All authors reviewed, refined, and approved the manuscript.

\section{References}

1. Irikura K, Bocchi N, Rocha-Filho RC, Biaggio SR, Iniesta J, Montiel V. Electrodegradation of the Acid Green 28 dye using Ti/beta- $\mathrm{PbO} 2$ and Ti-Pt/beta- $\mathrm{PbO} 2$ anodes. J Environ Manage 2016; 183: 306-13. doi: 10.1016/j. jenvman.2016.08.061.

2. Vargas AM, Cazetta AL, Martins AC, Moraes JC, Garcia EE, Gauze GF, et al. Kinetic and equilibrium studies: adsorption of food dyes Acid Yellow 6, Acid Yellow 23, and Acid Red 18 on activated carbon from flamboyant pods. Chem Eng J 2012; 181-182: 243-50. doi: 10.1016/j.cej.2011.11.073.

3. Gupta VK, Suhas. Application of low-cost adsorbents for dye removal--a review. J Environ Manage 2009; 90(8): 2313-42. doi: 10.1016/j.jenvman.2008.11.017.

4. Li X, Wu Y, Zhu W, Xue F, Qian Y, Wang C. Enhanced electrochemical oxidation of synthetic dyeing wastewater using $\mathrm{SnO} 2$-Sb-doped $\mathrm{TiO} 2$-coated granular activated carbon electrodes with high hydroxyl radical yields. Electrochim Acta 2016; 220: 276-84. doi: 10.1016/j. electacta.2016.09.109.

5. Mozia S,Tomaszewska M, Morawski AW. Photocatalytic degradation of azo-dye Acid Red 18. Desalination 2005; 185(1-3): 449-56.

6. Malakootian M, Asadi M, Mahvi AH. Evaluation of electroFenton process performance for COD and reactive Blue 19 removal from aqueous solution. Iranian Journal of Health and Environment 2013; 5(4): 433-44. [In Persian]. 
7. Movahedian Attar H, Rezaee R. Investigating the efficiency of advanced photochemical oxidation (APO) technology in degradation of direct azo dye by UV/H2O2 process. Journal of Water and Wastewater 2006; 17(3): 75-83. [In Persian].

8. Arqiani M, Jonidi Jafari A, Rezaeei Kalantary R, Gholami M. Study of the aniline removal from industrial wastewater by electrochemical process. Iran Occupational Health Journal 2013; 10(1): 70-8. [In Persian].

9. Zhang C, Jiang Y, Li Y, Hu Z, Zhou L, Zhou M. Threedimensional electrochemical process for wastewater treatment: a general review. Chem Eng J 2013; 228: 455-67. doi: $\quad 10.1016 /$ j.cej.2013.05.033.

10. Xiong Y, He C, Karlsson HT, Zhu X. Performance of three-phase three-dimensional electrode reactor for the reduction of COD in simulated wastewater-containing phenol. Chemosphere 2003; 50(1): 131-6. doi: 10.1016/ s0045-6535(02)00609-4.

11. Rabbani D, Mesdaghinia AR, Naseri S, Naddafi K. Effect of electrochemical process on phosphorous removal from activated sludge effluent. Feyz 2003; 7(3): 21-9. [In Persian].

12. Guivarch E, Trevin S, Lahitte C, Oturan MA. Degradation of azo dyes in water by electro-Fenton process. Environ Chem Lett 2003; 1(1): 38-44. doi: 10.1007/s10311-0020017-0.

13. Dalvand A, Gholami M, Jonidi Jafari A, Mahmoodi NM. Investigation of electrochemical coagulation process efficiency for removal of reactive Red 198 from colored wastewater. Journal of Color Science and Technology 2009; 3(2): 97-105. [In Persian].

14. Mehralipour J, Shabanlo A, Samarghandi M, Zolghadr H. Optimization of affecting parameters on performance of the electrocoagulation/electroflotation process by combine electrodes (Ti-Al) in Acid Black 1 dye decolonization in aqueous. Journal of Color Science and Technology 2015; 8(4): 325-32. [In Persian].

15. Rahmani A, Asgari G, Leili M, Aazami Gilan R. Degradation of methylene blue dye using fenton/photofenton-peracetic acid (UV/Fe3+-CH3COOH-H2O2) processes from aqueous solutions. Journal of Mazandaran University of Medical Sciences 2017; 27(153): 95-111. [In Persian].

16. Eslami A, Massoudinejad MR, Ghanbari F, Moradi M. Study on treatability of real textile wastewater by electrochemically generated fenton reagent using graphite felt cathode. Iranian Journal of Health and Environment 2012; 5(3): 273-82. [In Persian].

17. Ghanbari F, Kashi G, Dinpajouh H, Arabnia S, Mehdipour F. Decolorization of textile wastewater by electrochemical process in the presence of hydrogen peroxide and poly aluminum chloride. Journal of Water and Wastewater 2014; 25(1): 77-84. [In Persian].

18. Hossini H, Rezaee A, Hashemi SE. Electrochemical removal of hexavalent chromium from wastewater using PlatinumIron/Iron-carbon nanotubes and bipolar Electrodes.
Iranian South Medical Journal 2015; 17(6): 1203-12. [In Persian].

19. Moreira FC, Boaventura RA, Brillas E, Vilar VJP. Electrochemical advanced oxidation processes: a review on their application to synthetic and real wastewaters. Appl Catal B 2017; 202:217-61. doi: 10.1016/j.apcatb.2016.08.037.

20. Daneshvar N, Khataee AR, Amani Ghadim AR, Rasoulifard MH. Decolorization of C.I. Acid Yellow 23 solution by electrocoagulation process: investigation of operational parameters and evaluation of specific electrical energy consumption (SEEC). J Hazard Mater 2007; 148(3): 566-72. doi: $10.1016 /$ j.jhazmat.2007.03.028.

21. Massoudinejad MR, Yazdanbakhsh AR, Sharifi Maleksari H. Investigation of electrocoagulation process efficiency for color removal from polyacrylic textile industrial wastewater. Journal of Water and Wastewater 2013; 24(4): 40-8. [In Persian].

22. Safa S, Nasirizadeh N, Dehghani M, Ghaneian MT. Removal of Reactive Blue 19 Dye from Aqueous Solutions Using Sonochemistry Process in Presence of TiO2 Nanoparticles. Journal of Mazandaran University of Medical Sciences 2017; 27(154): 147-61. [In Persian].

23. Rajkumar D, Song BJ, Kim JG. Electrochemical degradation of Reactive Blue 19 in chloride medium for the treatment of textile dyeing wastewater with identification of intermediate compounds. Dyes Pigm 2007; 72(1): 1-7. doi: 10.1016/j. dyepig.2005.07.015.

24. Ozcan A, Sahin Y, Koparal AS, Oturan MA. A comparative study on the efficiency of electro-Fenton process in the removal of propham from water. Appl Catal B 2009; 89(34): 620-6. doi: 10.1016/j.apcatb.2009.01.022.

25. Samarghandi M, Shabanloo A, Mehralipour J, Kokabian M, Asgari Sorosh B. Comparison of electro-coagulation process (EC) and electro oxidation (EO) process for degradation of Acid Blue Dye 113(AB113) from aqueous solutions. Journal of Ilam University of Medical Sciences 2015; 23(1): 79-88. [In Persian].

26. Xiong Y, Strunk PJ, Xia H, Zhu X, Karlsson HT. Treatment of dye wastewater containing acid orange II using a cell with three-phase three-dimensional electrode. Water Res 2001; 35(17): 4226-30. doi: 10.1016/S0043-1354(01)00147-6.

27. Dehghan S, Rezaei Kalantary R, Nazari S, Moradi M, Rastegar A, Shirzad Siboni M. Optimization of dimethyl phthalate degradation parameters using zero-valent iron nanoparticles by response surface methodology: determination of degradation intermediate products and process pathway. Journal of Mazandaran University of Medical Sciences 2018; 27(157): 194-216. [In Persian].

28. Zazouli MA, Veisi F, Veisi A. Modeling bisphenol a removal from aqueous solution by activated carbon and Eggshell. Journal of Mazandaran University of Medical Sciences 2013; 22(2): 129-38. [In Persian]. 